Fall

\title{
Nicht verhungern, nicht verdursten - zum Problem der Sondenernährung
}

Herr A., ein 88jähriger Patient mit einem insulinpflichtigen Diabetes wird Anfang Juni in seiner Wohnung von seinem Hausarzt im Zustand einer deutlichen Exsikkose und hypoglykämisch vorgefunden und daraufhin in eine Geriatrische Klinik eingewiesen. Zu diesem Zeitpunkt bestand eine diabetische Gangrän am linken Fuß.

Am 19. Juni wurde Herr A. wegen einer Phlegmone am linken Fuß bei der bestehenden pAVK (peripheren arteriellen Verschlusskrankheit) Stadium IV in eine chirurgische Universitätsklinik verlegt. Dort musste eine Oberschenkelamputation links durchgeführt werden. Die Operation verlief komplikationslos, die Wunde heilte ausreichend gut. Herr A. verkraftete die Amputation jedoch sehr schlecht. Da er immer wieder Suizidgedanken äußerte, erfolgte am 27. Juni ein psychiatrisches Konsil, und die antidepressive Therapie wurde danach entsprechend umgestellt.

Am 1. Juli übernimmt eine junge Ärztin im Praktikum an ihrem ersten Arbeitstag den Bereich, in dem der Patient liegt. Herr A. bekräftigt auch ihr gegenüber beständig und mit Nachdruck, er wolle unter diesen Umständen nicht mehr leben. Er verweigert zunehmend Nahrung, Flüssigkeitszufuhr und Medikamente. Zudem zeigt er sich bei allen Maßnahmen und Bemühungen ganz und gar unkooperativ und nimmt bis auf $45 \mathrm{~kg}$ Körpergewicht ab.

Nach wenigen Tagen steht die Frage nach einer Sondenernährung bevor. Für die Ärztin im Praktikum stellt sich die Frage: Was tun? 